\title{
A Numerical Investigation of Segmental Lining Joints Interactions in Tunnels-Qomrud Water Conveyance Tunnel
}

\author{
Mohammad Hossein Ahmadi a , Ali Mortazavi ${ }^{\mathrm{b}}$, Seyed Morteza Davarpanah ${ }^{\mathrm{c}}$, \\ Hamid Zarei ${ }^{\mathrm{d}}$ \\ ${ }^{a}$ Ph.D. Candidate of Rock Mechanics, Department of Mining Engineering, Amirkabir University of Technology, Tehran, Iran \\ ${ }^{b}$ Associate Professor, Department of Mining Engineering, Amirkabir University of Technology, Tehran, Iran \\ ${ }^{c}$ Msc of Rock Mechanics, Department of Mining Engineering, Sahand University of Technology, Tabriz, Iran \\ ${ }^{d}$ Ph.D. Candidate of Rock Mechanics, Department of Mining Engineering, Amirkabir University of Technology, Tehran, Iran
}

Received 16 June 2016; Accepted 23 July 2016

\begin{abstract}
A comprehensive analysis of segmental lining joints can assist to guarantee a safe construction during tunnelling and serviceably stages. This paper has thoroughly investigated the interaction mechanism of precast concrete lining joints in tunnels. The Universal Distinct Element Code (UDEC), a two-dimensional numerical program based on the distinct element method (DEM) for discontinuum modelling, was implemented to simulated a typical segmental lining model consisting of six segment rings. In the analyses, the typical segmental lining design parameters of Qomrud water conveyance tunnel, aimed to transfer 100 million cu. m. water from the origins of Dez River to central Iranian desert, were employed to fulfil the purpose of the research. In the conducted analyses, the worst-case scenario of the loading faced during the boring of Qomrud tunnel was considered. This was highly associated with the existence of the crushed zone dipping at 75 degree at the location of the key segment. The worst scenario based on the condition that concerns the crushed zone intersect segmental lining at the location of key segment has been taken into consideration. In this study, the load acting on the joints of the segments includes the gravity load from the tunnel overburden and the crushed zone stratum force that intersects tunnel with 75 slopes at the location of the key segment, the gravity force of the segments and the earth pressure. The numerical investigation has been used for the different coefficients of stress concentration of $0.5,1,1.5,2$ and also different geological conditions of the saturated crushed zone under critical scenario.
\end{abstract}

Keywords: The Universal Distinct Element Code (UDEC); DEM Method; Contact Problem; Longtidunal Joint; Interface; Key Segment.

\section{Introduction}

One of the most challenging scenarios of mechanized tunneling is driving a tunnel boring machine (TBM) consistently through the mixed-face ground. In many cases, underground space development has reached the critical stage in which more favorable grounds for the excavation of underground structures have already been occupied. Tunnel layouts are often not determined according to the ground conditions, but the convenient available location and leading TBM through mixed/changing ground is an inevitable issue (Akos, 2013). Nowadays, due to lack of underground spaces for tunneling, many tunneling projects have been carried out in unfavorable ground conditions; this attitude certainly affects the precast system lining assemble by TBM after the excavation phase of tunneling. In the last decade, tunnels constructed with tunnel boring machine (TBM) have shown an increase of their diameter (Haak, 2000), and also the already congested underground space has obligated the excavation of tunnel at greater depths with unfavorable conditions leading to higher load levels [1].

\footnotetext{
* Corresponding author: m_davarpanah@sut.ac.ir
} 
The multi-segmental lining system has been widely adopted for the construction of underground tunnels in soft ground for decades. However, its complex ground-structure behavior has not been well understood and consequently has been overlooked. The popular choice of segmental lining in recent years has improved the speed of the construction and reduced the costs of tunneling; As a result, the design of linings has been a source of attention recently. The most challenging part concerns the factors that would induce stress in tunnel lining and causes a failure in segmental tunnel lining because of the contact problems. One of the determining factors affecting the stress induced in the lining is the effect of joints between segmental linings which has been often ignored. To comprehend this issue, the contact problem must be noted thoroughly. In fact, primary theory of the problem involves determining the total force and the moment acting at the joint that produces a deformation in segments compatible with its initial contact deficiency. Two types of joints exist in the segmental lining: longitudinal joints and circumferential joints; without considering the tunnel media, the contact problems exist in the segmental lining and needs to be solved prior to assembling the lining in tunnel construction. After installing the lining in tunnel, a new contact is created between a tunnel media and lining interface. It should be noted that most of the contact problem appears when uneven loading at the location of joints occurs. Results of the experimental studies by some researches show that the most frequent type of segment damage is caused by the condition of uneven segment matching due to contact deficiencies [1].

Tunneling projects are often seemed as the most challenging and costly civil engineering projects. This has motivated many authors to do researches to find out innovative ways to improve the constructability and stability of tunnels and reduce the high costs involved in tunneling projects. The design of a precast segmental lining is based upon the proposed tunnel alignment and the expected geological condition at the specified tunnel level. The geometrical arrangement of segment type might vary along a tunnel route and depends on the tunnel-boring machine steering alignment. This phenomenon affects the orientation of joints within each segmental ring. Another vital factor is the joint number that governs the possible mode of joint orientation. The combination of these two factors is likely to influence the stress distributed to the tunnel lining and directly affects the cost and planning purposes. The evolution and improvement of the modern tunnel boring machines (TBM) allows the construction of tunnels at increasing range of depths, dimensions and ground conditions. As the TBM advances, a segmental lining composed of multiple adjacent concrete rings is continuously placed (Figure 1). This segmental lining provides both structural capacity to resist the ground, water pressure and necessary reaction frame to push the TBM ahead.

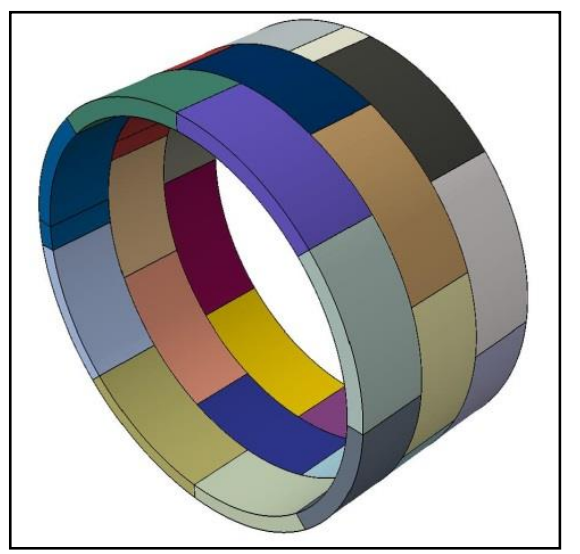

Figure 1. Staggered concrete segment tunnel lining

Recently, some research programs have been promoted in order to analyze the segmental tunnel lining behavior subjected to the longitudinal, circumferential uniform design loads and geological conditions. Uneven longitudinal ground settlements may lead to over-stress on a tunnel concrete segmental lining. The stress concentration is likely to induce lining segment cracking, joint bolts yielding, joint dislocation and joint tension crushing, which can result in serious slurry and water leakage problems. These issues may bring great risk to metro operations and also cause serious risks to the people travelling by subway. Therefore, the failure mechanism of tunnel lining with uneven longitudinal ground settlement should be determined, insuring normal operations of metro, especially in deep soft soil (Zhan Wang, 2014). There are usually concentrated cracks distributed along the lining segment at their dislocations, created by uneven longitudinal ground settlement; so, it is necessary to consider the evolution of cracks to evaluate the capability of tunnel concrete segmental lining. This leads to a nearly impossible task on the current desktop computer, even when just considering the nonlinear contact system with possible diffusion cracks. This paper mainly emphasizes the circumferential joint behavior. To achieve this aim, the tunnel lining consisting of segments and connected by circumferential bolts, is deliberately simplified as a homogeneous ring in order to save computational resources, and the effective rigidity ratio of the lining ring is assumed to be 0.7 , according to the soft soil tunnel experience (Blom, 2002) [1]. The lining concrete is assumed to be elastic to improve numerical convergence, along with the help of stress concentration to show possible cracking. Main conclusion pointes out the increase in lining instability caused by joints opening and contact deficiencies, reducing the experienced deformation and increasing the internal bending forces. 
Blom developed an analytical model to study the effect of different circumferential joint stiffness for a certain tunnel case. He concluded that stiffer joints imply a significant increase of the ring internal bending forces (from 1.3 to 1.8 times, the values obtained with the isolated ring), and a minor reduction on the movements, in comparison with those obtained by the isolated ring model [1]. Oriol Arnau studied a phenomena associated with the coupling effects and determined the main parameters involved, and analyzed the influence of these parameters on a real lining structural response employing a 3D numerical model. He concluded that when a segmental tunnel lining is subjected to a longitudinally distributed load, the staggered configuration of its joints produces the activation of force interaction mechanisms between adjacent rings, originating the so-called coupling effects [2]. Ashraf Mohamed Hefny investigated the factors affecting the maximum bending moment induced in a jointed tunnel lining. His Observations demonstrated that increasing joint number reduces the maximum bending moment induced to the lining. However, the effects of joint number and orientation on the maximum bending moment induced to the tunnel lining become insignificant once the critical joint number has been exceeded [3]. One of the most important factors in designing a segmental tunnel lining is the influence of segmental joints on its overall bending moment carrying characteristics. This is mostly due to the difficulty in providing segmental joints to be as stiff as the main segment. Engineers usually allow segmental joint to be less stiff and undergo more deformation than the main portion, which leads the joint to be the most critical part of lining. Contact mechanics plays an important role in a multitude of physical and tri-biological mechanisms. Researchers have intensively studied solid interfacial phenomena involving sliding friction and adhesion [4].

Several model tests have recently been carried out to examine the influence of joints on lining behavior. Lu (2008) conducted an experimental study to investigate the load carrying capacity of a fully segmental reinforced concrete lining with an outer diameter of $15.0 \mathrm{~m}$. A great deal of useful information was obtained; unfortunately, however, the influence of segmental rotational stiffness was not explored in detail. Teachavorasinskun and Chub-Uppakarn (2008) performed a series of laboratory tests which were carried out on a scaled segmental tunnel $(15 \mathrm{~cm})$ made from PVC, in order to estimate the applicability of the simple beam support in terms of the bending moment reduction factor. However, the influence of the surrounding ground on the calculated results was not considered [5].

Hefny and Chua (2006) numerically studied the influence of the joint number, joint orientation, lateral earth pressure factor, and tunnel depth on the bending moment induced in a $6 \mathrm{~m}$ diameter segmental tunnel lining, using a finite element analysis program. In their analyses, the stiffness of the segmental joint was not considered. Arnau and Mo-lins (2011) carried out a real scale test on an experimental tunnel section of the new Line 9 of the Barcelona underground metro system. The section was composed of 15 rings built using only steel fibers as the reinforcement. The contact between the longitudinal joints was modeled using unilateral interface elements located at one side of plastic packer elements. The in situ measurements and the results of the numerical simulation were similar in terms of displacements, joint closures and crack patterns [6].

It is known that the contact deficiencies are the result of a complex sum of several tolerances on the shape and on the placement of the segmental lining. In addition to that, the construction process of the tunnel magnifies the imperfection expected of a single isolated ring. The overall consideration of this phenomenon yields an intricate analysis that must take into account some important probabilistic aspects. Only that would make possible the assessment of the role played by the tolerances both on the formation of the contact deficiencies and on the damages produced throughout the construction process. On a further step, this would also increase the knowledge about the behavior of the lining, thus contributing to the proper definition of the tolerance during the design of the structure [6].

In previous studies, many longitudinal models have been proposed, among which the most typical ones include the beam-spring model proposed by Koizumi (1988), and the longitudinal continuous model proposed by Shiba (1988). In the beam-spring model, the segmental rings are simplified as short beams and the circumferential joints are modeled by axial, shear, and rotational spring elements. The weakness of the beam-spring model is its computational complexity in solving the analytical problem. Meanwhile, the rigidities of springs in joints are always difficult to determine. In contrast, the longitudinal continuous model regards the tunnel as a homogenous beam in the longitudinal direction, which makes the calculation simpler. This model has been widely adopted for analyzing the internal forces and the deformation of a tunnel by combining the Euler-Bernoulli beam theory [7].

The objective of present work is to explain and predict contact deficiencies in segmental lining joints interactions prior to segmental lining design. In fact, primary theory of the problem involves determining the total force and the moment acting at the joint that produces a deformation in the segments compatible with its initial contact deficiency. A key point related to the segmental lining joints interactions is surpassing the contact problems and overcoming the difficulties related to interfaces.

\section{Two-Dimensional Numerical Modeling of Tunnel Lining}

The numerical procedures which are implemented in the prediction of tunnel behavior are mostly created for designing purposes. This fact allows the assumption of certain hypotheses that simplify the solution by providing 
safety results. On the other hand, the reproduction of the real response requires an adequate consideration of all parameters involved in such behavior. As a result, it is crucial to clearly define them and develop numerical strategies for their accurate simulation. It is of great importance to realize that similar precast concrete thickness is adopted for jointed tunnel lining and no longitudinal devices exist between the segments of the ring.

In order to perform a study on a real basis, the typical section of six segments of Qomrud water conveyance tunnel was simulated to reduce the computation time; the numerical model consists of six segments; information about segment dimensions, detailed construction arrangement and numbering are depicted in Figure 2. As it is shown, segment external diameter is $6 \mathrm{~m}$; internal diameter is $5.4 \mathrm{~m}$, and thickness is $0.3 \mathrm{~m}$. One segment ring consists of one key segment (KP), two adjacent segments (BP and CP) and three standard segments (A1P-A3P). The key segment deviates 18 degree from the vertical direction.

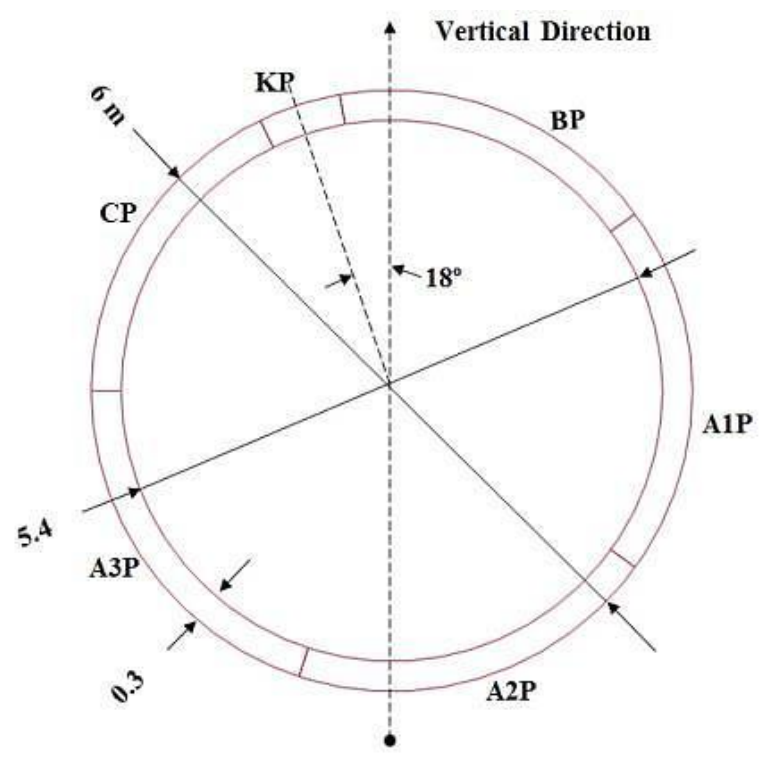

Figure 2. Segment arrangement and numbering

In addition to the joints behavior, the Crushed stratum-structure interaction has significant effect on the structural response of lining. A ring of segmental lining is a multiple hinged structure and its stability against the applied loads depends on the surrounding ground response. Moreover, the key segment plays an important role in segmental lining stability. For this purpose, in this paper we have studied only geological section in which the crushing zone stratum intersect tunnel lining at the location of the key segment joint.

In order to consider the real loading condition on the segment lining, the crushed zone stratum with 75-degree gradient and $2.5 \mathrm{~m}$ thickness that intersects segmental ring at the location of the key segment was defined as shown in Figure 3.

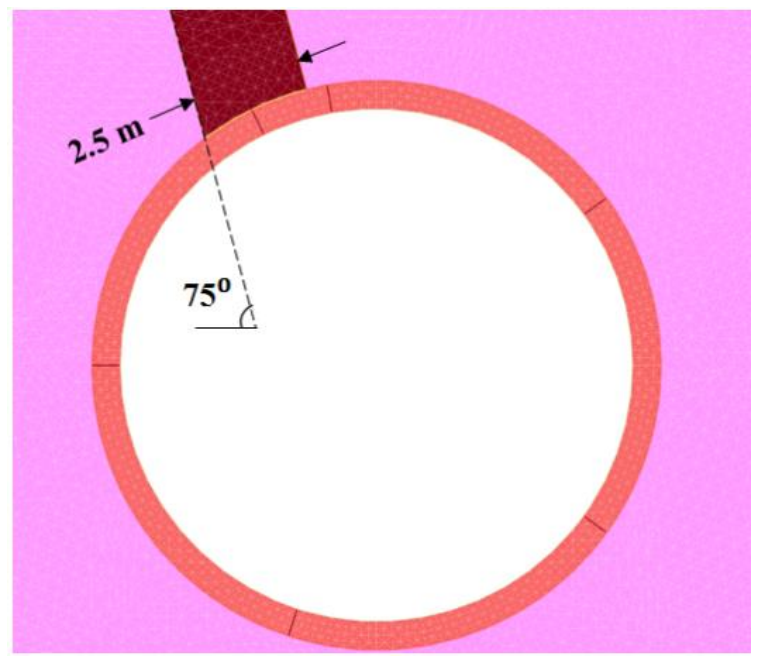

Figure 3. Crushed zone and ring interaction 
In this study, the most critical circumstances were considered for the crushed zone. The worst scenario occurs when the crushed zone is perpendicular to the tunnel crown and intersects tunnel lining at the location of key segment simultaneously. In this situation, the entire load of the crushed zone acts on the lining system. Although the tunnel is located at the depth of $500 \mathrm{~m}$ underground, in the numerical modeling only $20 \mathrm{~m}$ of the overburden was applied and the remaining load was imported as an external equivalent load. Equivalent gravity loads of the crushed zone were calculated according to the Terezaghi's overburden load criteria. So, for decreasing time step in numerical simulation, the equivalent loads acts on the crushed zone- segment interface according to Terezaghi's overburden rock load in Figure 4.a. The distributed equivalent load paradigm on the segment-stratum interface is depicted in Figure 4.b. The weak stratum acts as an uneven loading on the circular tunnel lining; this uneven type of loading introduces high shear and tensile stress which threatens the stability of the circular concrete structures [8].
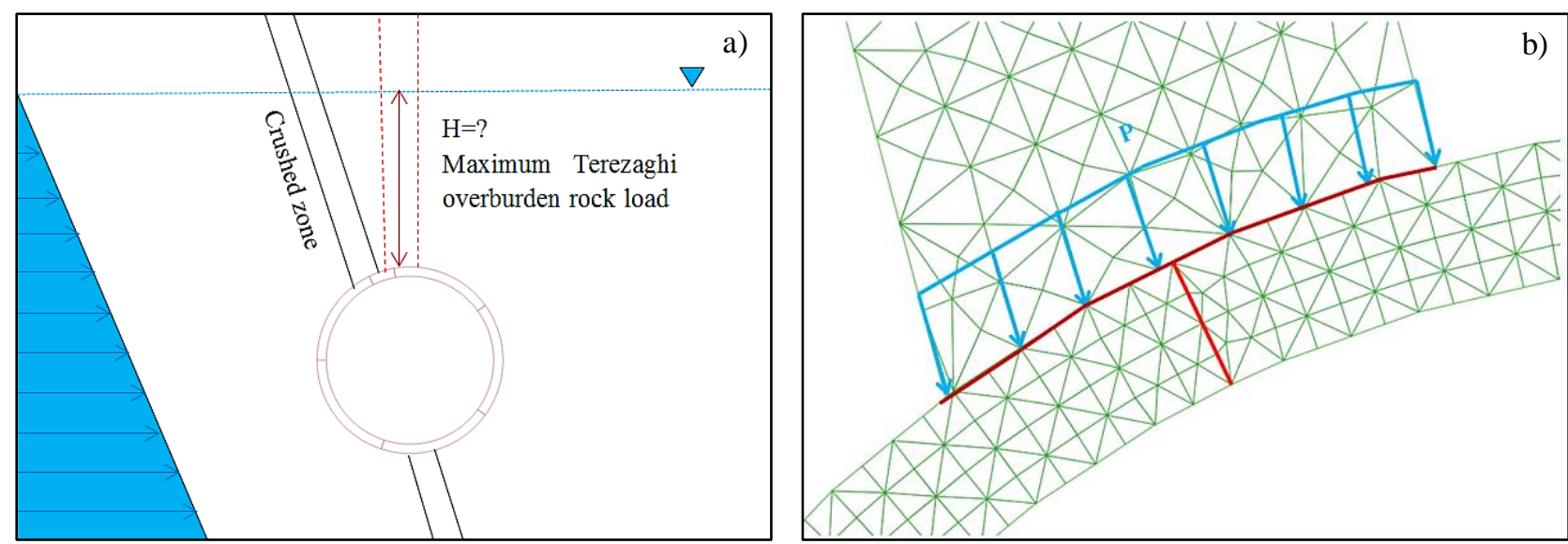

Figure 4. a) The worst scenario of the crushed zone, b) Applying the equivalent load on the segment-stratum interface

\section{Interfaces and Segmental Lining Modeling}

\subsection{Interface Theory}

According to the Interface theory, when the physical parameters such as density and stiffness change, the altered boundaries behave as an interface (Figure 5). The examination of materials and structures illustrates that homogeneity is an assumption to simplify the reality. Interfaces normally exist at different scales and influence the properties of material and structural responses. An interface is represented between two adjacent planes by a normal stiffness and shear stiffness $\left(K_{n}\right.$ and $\left.K_{s}\right)$. In order to create a model an interface, the following properties of material are required:

- $K_{n}$ : Normal stiffness

- $K_{s}$ : Shear stiffness

- $\quad C$ : Cohesion

- $\varphi$ : Friction angle

- $\sigma_{t}$ : Tensile strength

The interfaces used in this study allow slip and separation in defined numerical modeling. For this type of interface, the strength properties such as friction angle $\varphi$, cohesion $\mathrm{c}$ and tensile strength $\left(\sigma_{t}\right)$ are more important than the stiffness properties (Itasca 2008) [9].

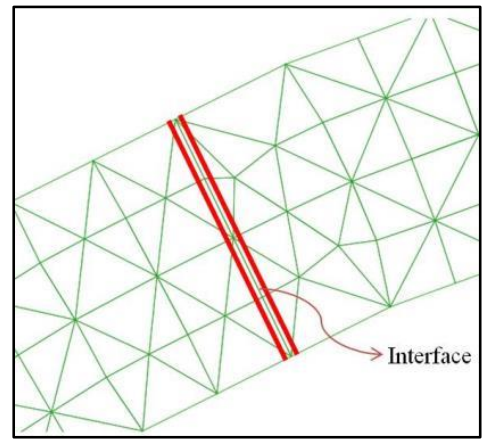

Figure 5. Definition of interface between materials 


\subsection{Essential Interfaces}

In comparison to the dimensions of concrete blocks which are around $(0.3 \mathrm{~m} \times 1 \mathrm{~m})$, segmental lining systems are likely to have some joints; these joints are very thin (12-18 $\mathrm{mm}$ in thickness). However, these joints serve an indispensable function in the mechanical behavior of whole segmental lining system. In order to devise a better simulation of the real joint response, several sophisticated approaches have been proposed in the contact elements modeling. Reviewing the available technical literature on this issue reveals four main categories of contact models for assessing the effects of longitudinal joints on liner internal forces as follows:

Using hinges at liner contact points (HL model): In this method, segments are modeled using beam elements considering perfect hinges in their contact locations. Assuming perfect joints in the liner causes a pure axial force in the joint location without any bending moment. The joint behavior in this model cannot consider the flexural behavior of segment-to-segment contact area and leads to the transfer of bending moment to segments. This method usually causes more bending moment in the liner than other contact models. Tang and Zhong have utilized this method for structural analysis of segmental lining.

Reducing liner rigidity (RR model): Some researchers and societies such as Japan Society of Civil Engineers (JSCE), Ranken, Einstein and Schwartz, Yuen, Ogawa, Liu and Hou, Lee and Ge, Blom, and El Naggar have considered segmental tunnel lining as a continuous ring with discounted rigidity by applying a reduction factor to the bending stiffness (EI) of liners.

Beam rotational spring model (BRS model): In this model, segments are modeled by beam elements and longitudinal joints using rotational springs. Many researchers have proposed various values for rotational stiffness. For instance, Mashimo and Ishimura suggested the range of 32-127 MN m/rad for this parameter. Lee proposed the range of 4-30 MN m/rad for such stiffness, which was based on the field measured values reported by Chen and Zhou in Shanghai subway tunnel. Koyama proposed three diagrams for bending moment versus rotational angle $(M-\theta)$ behavior of contact joints in segmental lining. In their study, approximate values of rotational spring stiffness $\left(K_{\theta}\right)$ as the slope of $(M-\theta)$ diagrams varied from 15 to $150 \mathrm{MN} \mathrm{m} / \mathrm{rad}$. Teachavorasinskun and Chub-uppakarn, according to the experimental tests and FEM modeling, suggested the range of $1-3 \mathrm{MN} \mathrm{m} / \mathrm{rad}$ for $\left(K_{\theta}\right)$. In another study, Arnau and Molins presented the rotational stiffness of segments as 50 and $100 \mathrm{MN} \mathrm{m} / \mathrm{rad}$ with respect to two values of compressive stress as 1.5 and $3 \mathrm{MPa}$ in the contact location [8].

By summarizing the above mentioned models, it could be stated that the first method does not simulate properly the actual construction conditions and considers joints as a hinge while ignoring partial moment transmitting capacity. On the other hand, although effective bending rigidity must only affect contact points, in the second model, it affects the entire lining by ratio of the bending rigidity. In the third model, it is assumed that all segments have the same length in a ring, which is not correct in most of practical cases. In sum, it can be stated that all of the aforementioned methods have ignored the relevance of normal and tangential stiffness of contact points to the normal stress acting on contact surfaces [10].

Modeling a segmental tunnel lining involves several components including precast concrete segments, seal materials in the joints and backfill grouts. To assemble the model, DEM (distinct element method) was applied to create the numerical model for this case; however, mesh generation stage have some limitations in the numerical modeling; therefore, solid elements with low thickness cannot be used to represent these materials. To solve this problem, in this research, the interface elements with appropriate properties have been defined to represent these components. An interface is defined by normal and shear stiffness $\left(K_{n}\right.$ and $\left.K_{s}\right)$ between two planes which may contact each other. Contact function is applied to simulate the interaction of each sliding material and the Squeezing action is another important consideration induced by the crushed zone and the ground reaction is also of high importance simulated by the contact function [11].

The circular gap between rock mass and tunnel lining system usually contains a hydrating grout material; In order to complete the simulation process, it is very important to ascertain the stiffness of the hydrating grout material. Simultaneously, the thickness of hydrating grout material is relatively thin and unclear. Therefore, for simulating the interaction between tunnel lining and around rock mass, the hydrating grout materials are usually not considered and contact surfaces are set between the inner surface of rock mass and the segment exterior surface. When the tunnel structure deforms under the earth pressure, the contact interaction between rock mass and segments can restrict the tunnel deformation. That is, Contact forces include normal force and sliding- frictional force that prevent further deformation. So, in some numerical simulations, radial ground reaction spring and tangential ground reaction spring in traditional load-structure model can be replaced by rock mass with contact surface. The spring stiffness of traditional model is substituted by Young's modulus of rock mass that changes with different crushed zone stratum. All of the interfaces including segment-segment interfaces, segment-around rock mass interfaces, segment-crushed zone stratum interfaces, and segment- crushed zone stratum interfaces which are shown in the below picture (Figure 6). 


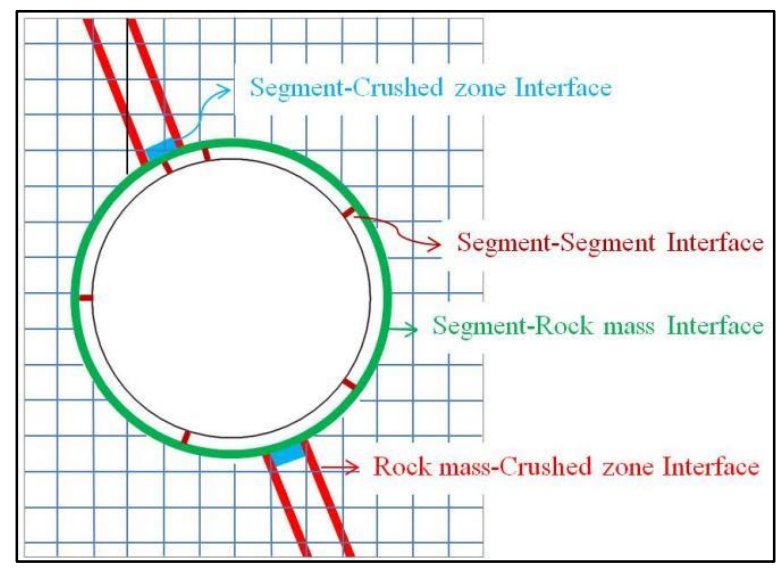

Figure 6. Different interfaces in numerical modeling

In order to determine the real parameters of interfaces, some laboratory tests should be consider even though high expenditures and test's scale restrict laboratory test implementation. Additionally, the evaluation of ground response against the ring deformation is the main limitation of these tests. Interfaces parameters are summarized in Table 1. Note that, the weakest values in the sides of interface are selected as the cohesion and friction angle parameters $[11,12]$.

Table 1. Interface parameters in numerical modelling

\begin{tabular}{|c|c|c|c|c|c|}
\hline Interface & $\begin{array}{c}\text { Normal Stiffness } \\
(\mathbf{G P a} / \mathbf{m})\end{array}$ & $\begin{array}{c}\text { Shear Stiffness } \\
(\mathbf{G P a} / \mathbf{m})\end{array}$ & \multicolumn{2}{|c|}{ Cohesion (KPa) } & Friction angle \\
\hline Segment-Rock mass & 40 & 31 & \multicolumn{2}{|c|}{900} & 32 \\
\hline \multirow{3}{*}{ Rock mass-Stratum } & \multirow{3}{*}{2} & \multirow{3}{*}{1.4} & Marl & 900 & 32 \\
\hline & & & shale & 450 & 28 \\
\hline & & & Sandstone & 50 & 25 \\
\hline \multirow{3}{*}{ Segment-stratum } & \multirow{3}{*}{40} & \multirow{3}{*}{31} & Marl & 900 & 32 \\
\hline & & & shale & 450 & 28 \\
\hline & & & sandstone & 50 & 25 \\
\hline Segment-Segment & 40 & 31 & \multicolumn{2}{|c|}{0} & 46 \\
\hline
\end{tabular}

\subsection{Materials Properties}

The typical section of Qomrud water conveyance tunnel was used for modeling the circumference of the tunnel. Various materials such as the different rock mass types and concrete blocks are involved in this procedure which was modeled by using Mohr-Coulomb failure criteria. Table 2 shows the properties of surrounding rock masses.

In this paper, different situations for the crushed zone materials have been studied. Considering different climate conditions and the effect of underground water, the properties of the crushed zone may alter. It's also important to realize that in some special cases squeezing effects might occur. To understand this, first, Marl properties was assigned for the crushed zone stratum materials. Although Marl is a weak rock and compared to the other rock types at Qomrud water conveyance tunnel easily weathers on exposure, Patchet (1970) mentioned that in most conditions marl shows plastic behavior and probably has no tensile strength. For having a good evaluation, the properties of marl stratum under changing geologic condition are associated with the properties of Shale and Sandstone. Geotechnical properties of these materials are given in Table 3.

Table 2. Properties of surrounding rock (Marl)

\begin{tabular}{lc}
\hline Density $\left(\mathrm{Kg} / \mathbf{m}^{\mathbf{3}}\right)$ & 2600 \\
Saturated Density $\left(\mathrm{KN} / \mathbf{m}^{\mathbf{3}}\right)$ & 2.75 \\
USC $(\mathrm{MPa})$ & 30 \\
Cohesion $(\mathrm{KPa})$ & 900 \\
Frictional angle & 32 \\
Young's modulus $(\mathbf{G P a})$ & 1 \\
Poisson's ratio & 0.23 \\
Geological strength index (GSI) & 30 \\
Porosity (e) & 0.2 \\
\hline
\end{tabular}


Table 3. Geotechnical properties of crushed stratum

\begin{tabular}{cccccccc}
\hline Material & $\boldsymbol{\gamma}\left(\mathbf{K g} / \mathbf{m}^{\mathbf{3}}\right)$ & $\gamma_{\text {sat }}\left(\mathbf{K N} / \mathbf{m}^{\mathbf{3}}\right)$ & $\mathrm{e}$ & $\mathbf{C}(\mathbf{K P a})$ & $\mathbf{E}(\mathbf{M P a})$ & $\boldsymbol{\varphi}$ & Poisson's ratio \\
\hline shale & 2200 & 2.5 & 0.4 & 450 & 500 & 28 & 0.29 \\
Sandstone & 2000 & 2.3 & 0.6 & 50 & 350 & 25 & 0.32 \\
\hline
\end{tabular}

According to the aforementioned texts, in order to consider the worst scenario of loading, the equivalent load of the saturated overburden rock was calculated by using Terzaghi's rock mass load theory at different levels where water existence above the tunnel overburden $(30 \mathrm{~m}, 35 \mathrm{~m}$ and $40 \mathrm{~m})$. The results are summarized in Table 4.

Table 4. Equivalent load of saturated overburden rock according to Terzaghi rock load theory

\begin{tabular}{c|cc}
\hline \multirow{2}{*}{ Material } & $\begin{array}{c}\text { Embedded depth above the tunnel } \\
\text { H (m) }\end{array}$ & $\begin{array}{c}\text { Equivalent saturated overburden rock load } \\
(\mathbf{K N})\end{array}$ \\
\hline \multirow{3}{*}{ Marl } & 30 & 207.5 \\
& 35 & 242 \\
& 40 & 276.5 \\
\hline \multirow{3}{*}{ Shale } & 30 & 214 \\
& 35 & 217.5 \\
& 40 & 248.5 \\
\hline \multirow{3}{*}{ Sandstone } & 30 & 178 \\
& 35 & 208 \\
& 40 & 233.5 \\
\hline
\end{tabular}

The Segment lining parameters used in the numerical simulation are presented in Table 5. The model parameters used in the segmental lining were selected based on the national and international shield tunnelling experience.

Table 5. Segmental lining properties used in the analyses

\begin{tabular}{cccccc}
\hline $\begin{array}{c}\text { Density } \\
\left(\mathbf{K g} / \mathbf{m}^{\mathbf{3}}\right)\end{array}$ & $\begin{array}{c}\text { Young's modulus } \\
(\mathbf{G P a})\end{array}$ & Poisson's ratio & $\begin{array}{c}\text { Cohesion } \\
(\mathbf{M P a})\end{array}$ & Frictional angle & $\begin{array}{c}\text { Tension strength } \\
(\mathbf{M P a})\end{array}$ \\
\hline 2700 & 24 & 0.2 & 5 & 46 & 4 \\
\hline
\end{tabular}

\section{Analysis of Numerical Modeling}

The Universal Distinct Element Code (UDEC) is a two-dimensional numerical program based on the distinct element method for dis-continuum modeling. UDEC simulates the response of discontinuous media (such as a jointed rock mass) subjected to either static or dynamic loading. The discontinuous medium is represented as an assemblage of discrete blocks. The discontinuities are treated as boundary conditions between blocks; large displacements along discontinuities and rotations of blocks are allowed. Individual blocks behave as either rigid or deformable material. Deformable blocks are subdivided into a mesh of finite-difference elements, and each element responds according to a prescribed linear or nonlinear stress-strain law. The relative motion of the discontinuities is also governed by linear or nonlinear force-displacement relations for movement in both the normal and shear directions. UDEC is based on a "Lagrangian" calculation scheme that is well-suited to model the large movements and deformations of a blocky system (Itasca Consulting Group Inc, 2015).

The DEM approach is the well-recognized numerical tool to analyze geotechnical projects due to its ability to take into account the heterogeneity of ground, the non-linear behavior of rock mass, the complex geometry of works and the method of construction. Squeezing action induced by a stratum can be modeled as the contact interaction between the crushed zone and the segments. Thus, the contact interaction is capable of simulating squeezing action.

The loading process of tunnel lining has been divided into two steps:

First, the earth pressure around the tunnel was applied to simulate the initial state of the tunnel; moreover, the effect of changes in the horizontal stress ratio of the loads on the segment was assessed. The boundary condition associated with $\mathrm{K}$ (ratio of horizontal to vertical stress) values of $0.5,1,1.5$ and 2 were applied to the model and also separate analysis was conducted for each case. Second, the uneven load from the calculation of equivalent load of $500 \mathrm{~m}$ caused by tunnel overburden was imported in the crushed zone and the tunnel lining interface. 
As an individual ring is loaded (Figure 7), it deforms according to its flexibility until the ground provides the necessary reaction to equilibrate the loads. The parameters of interface between high strength concrete blocks in the Segmental lining improve the flexibility of lining system successfully, but decrease the strength of whole lining system as weak "joints". The ground deformations occur to achieve such reaction and depend on the circumferential ground stiffness; therefore, it will play a decisive role on the radial displacements experienced by the ring (Figure 7). While the concrete segments remain undamaged (with no cracks), the movements of ring are mainly caused by concentrated deformation in longitudinal joints to obtain reasonable results based on the conservative assumption that the lining segments are rigid. It means that all the lining distortion and rotation would take place only at the location of joints [13].
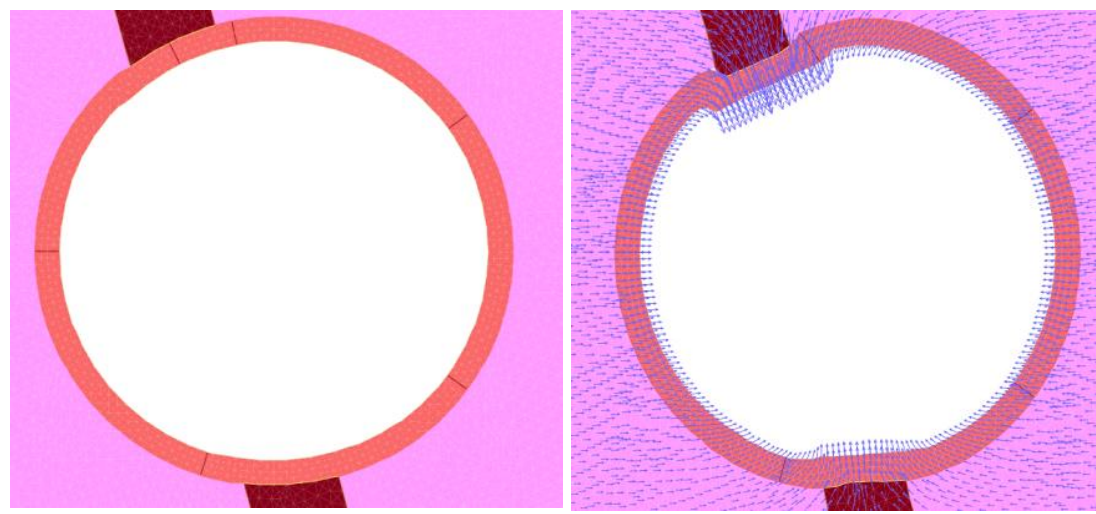

Figure 7. Squeezing load effects on the segmental lining and formed deformation

Figure 8. Shows the Segmental lining deformation for stratum condition specified for Sandstone properties and embedded depth $40 \mathrm{~m}$ above the tunnel at various stress fields. It's obvious that as the strength of stratum material decreases and the coefficients of stress concentration increases contemporaneously, the deformation of segmental lining at the crushed zone-segment interface soars. Besides, for the coefficient of stress concentration of two $(K=2)$, the deformation around the key segment is symmetric.
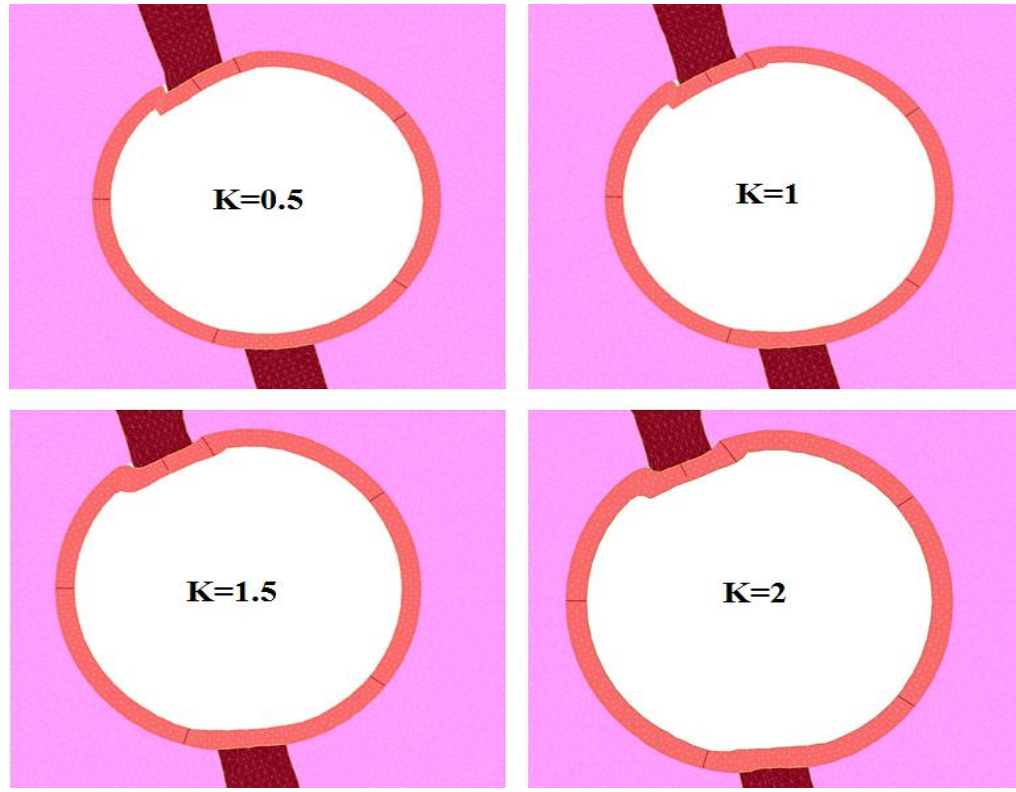

Figure 8. Deformation of the segmental lining at different stress fields

According to Figure 8, deformation of the segmental lining is the curved shape and its convergence is toward to the inner side of the tunnel. It's due to this fact that the trapezoidal shape of segments, the exterior radius of the segments, is greater than the interior radius of them. Thus, the magnitudes of loads from peripheral rock mass must be high enough to dominate the hatched area in Figure 9, which is in fact, impossible in real loading condition. 


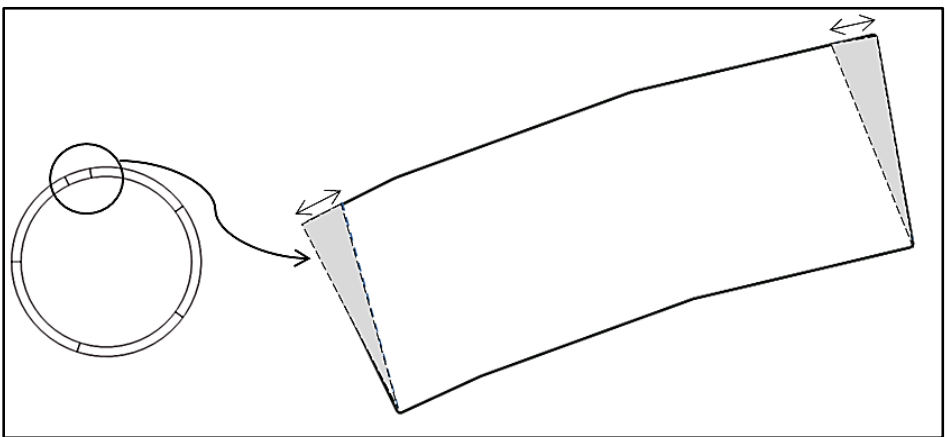

Figure 9. Representation of the segment trapezoidal shape

The other important factor that needs to be addressed is the bending moment. In order to discover the impact of this factor in the deformation of the segmental lining, the Induced bending moment at the location of the key segment that interacts with the crushed zone was investigated. The results are show in Figure 10 for different following statuses:

- Stratum condition set according to Marl, shale and Sandstone properties

- Equivalent local load of the segment-stratum interface according to the embedded depths of $30 \mathrm{~m}, 35 \mathrm{~m}$ and $40 \mathrm{~m}$ overburden above the tunnel

- $\quad$ The dominant stress fields set for $0.5,1,1.5$ and 2
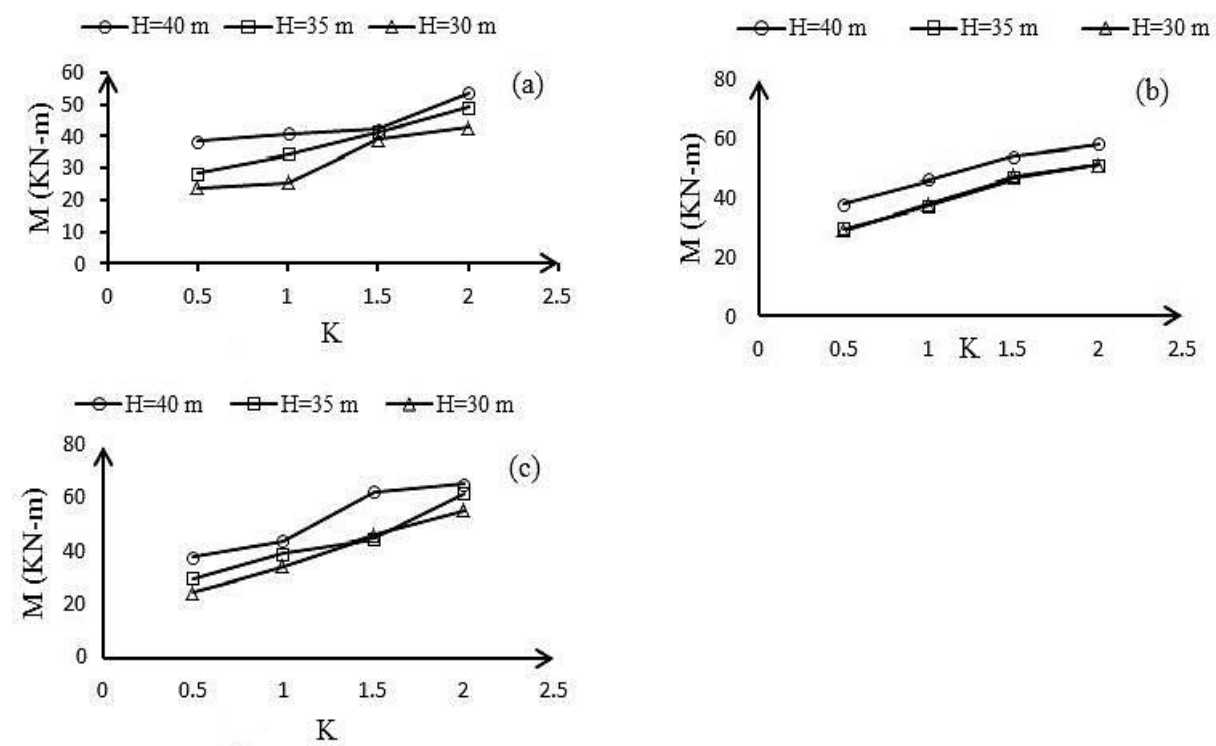

Figure 10. Induced bending moment in longitudinal joint at the location of the key segment and the crushed zone interface

\section{a) Marl b) Shale c) Sandstone}

It can be inferred from the above results that the strengthening of circumferential shear stiffness with staggered segment joints will result in the reduction of additional deformation and bending moment at the cross section of the tunnel. However, it should be noted that the increase in stress concentration coefficient simultaneously leads to the increase in the bending moment of the cross section at longitudinal joint.

The calculated results also show that the bending moment at the longitudinal joint decreases as the circumferential stiffness and embedded depth above the tunnel go up. Therefore, it is highly recommended that for an effective tunnel lining design, the bending stiffness should be reduced and the shear stiffness should be increased to reduce the additional forces and increase the longitudinal stability of the tunnel under the ground differential stiffness. It can also be concluded that the additional moment in the joint is closely related to the shear forces produced by longitudinal ground displacement.

Under the local loading at the Segment-Stratum, the interface opening of the longitudinal joint occurs. Increasing the local load influences the longitudinal joint ability at the transition of structural loads. When opening of the joints occurs, joint interaction remains just at the points that two segments have a contact with each other. Figure 11 shows the joint opening at the location of the key segment and the crushed zone interface. 


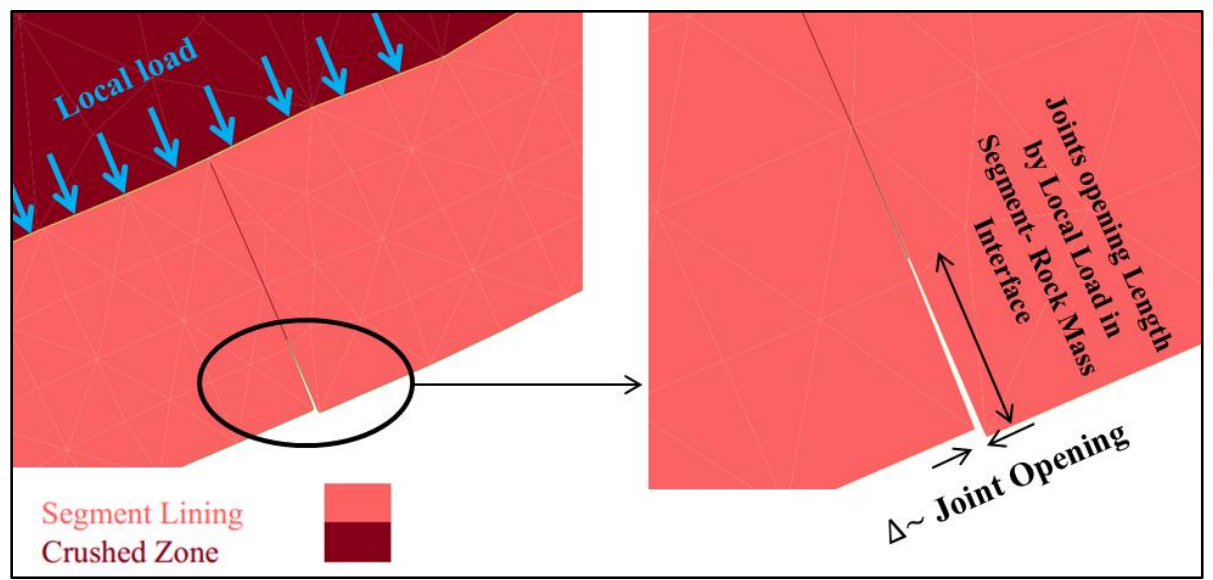

Figure 11. Geometrical definition of the opening and opening length at longitudinal joint

The relationship between the coefficient of stress concentration and the opening length of joint is shown in Figure 12. The curves show the changes at the gradient caused by the applied local load and resultant opening length in the joint for the different coefficients of stress concentration. The increase in the embedded depth above tunnel intensifies the squeezing load at the segment-stratum interface. However, Complex loading condition for defined interface may lead to irregular relation between the opening length of joint (r) and the coefficient of stress concentration $(\mathrm{K})$.

After tunnel excavation, tangential stress is induced immediately in lining. As time goes on, the radial stress induced in lining is affected by the earth pressure and other types of loading at the segment-rock mass interface, especially at the location of longitudinal joint that increase in the radial stress causes opening in the joints. In addition to imposing the relevant joint opening along the longitudinal joint, the suggested special study for specified geological condition applies load to the rings at the location of joints.
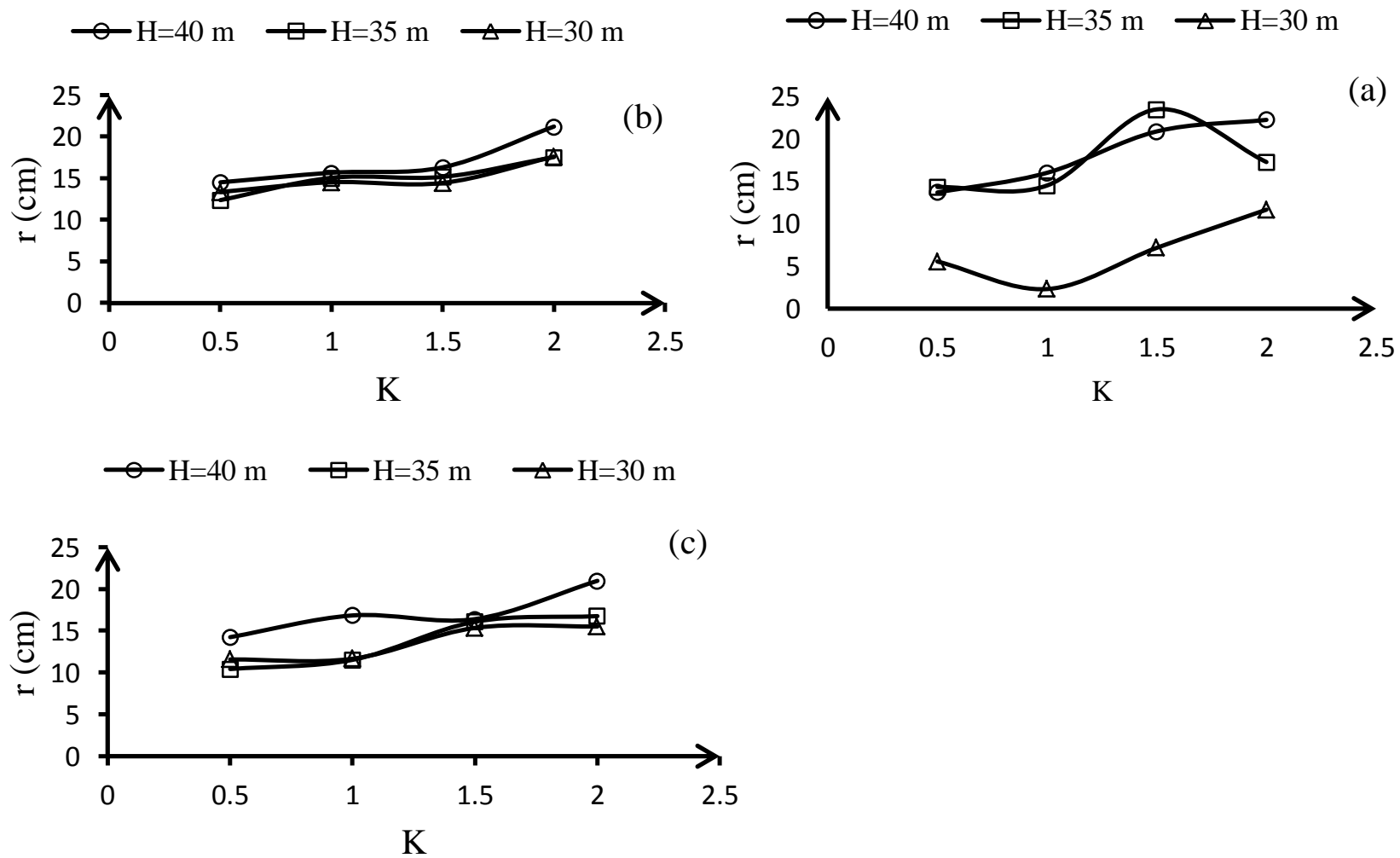

Figure 12. Relationship between the coefficient of stress concentration and opening length at the location of the key segment and the crushed zone interface a) Marl b) shale c) sandstone

For further analysis, Investigations also were conducted to study the interaction mechanism of segmental lining joints. In order to fulfill this purpose, the interaction between the induced radial stress and the joint opening length at the location of the key segment joint has been taken into consideration and the results are depicted in Figure 13. As it 
was mentioned earlier, each material assigned to stratum has the specific strength and geotechnical parameters; comparing the results for different stratum materials (Marl, Shale and Sandstone) doesn't seem a logical way; therefore, the results must be interpreted particularly for each case under different loading conditions .

According to the results from Figure 13, induced radial stress increases as the local load at the segment-stratum interface goes up. (Proportional to the increase in embedded loose depth above tunnel). Moreover, the strength of stratum materials impacts the joint opening length and lining induced radial stress in the sides of joint. The Increase at the crushed materials in stratum causes the increase in joint opening length (increase in active squeezing load to the ring at the segment-Stratum interface).
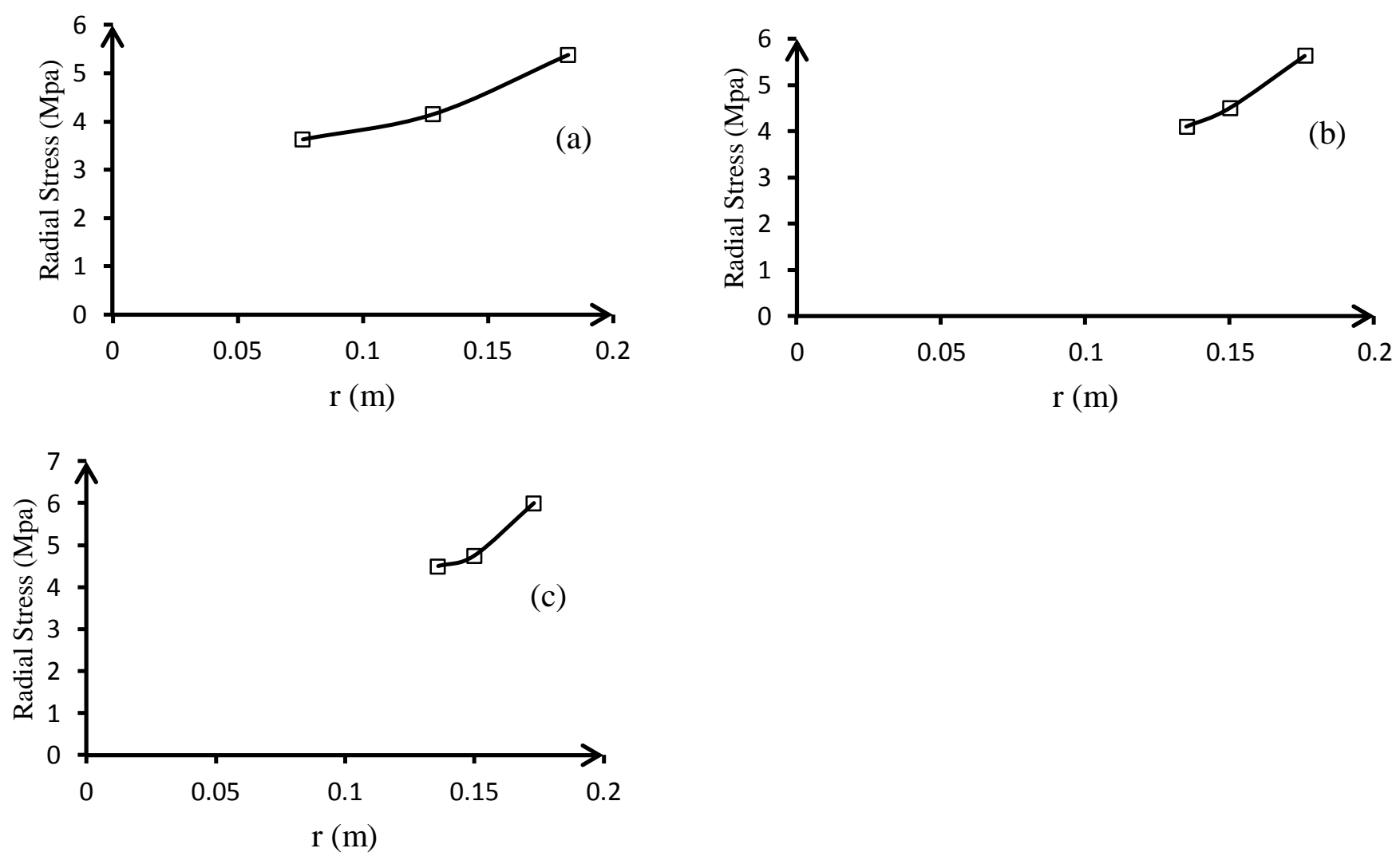

Figure 13. Induced radial stress vs. joint opening length for different material properties a) Marl b) Shale c) Sandstone

Similarly, the interaction between joint opening $(\Delta)$ and joint opening length (r) was probed. The influence of squeezing active load on the longitudinal joint opening at the segment-stratum interface is depicted in Figure 14. The Accurate interpretation of Figure 13 proves direct relationship between joint opening and local load from the squeezing load proportional to the embedded loose zone above the tunnel. In other words, the decrease of the strength of stratum materials (high crushed materials) leads to the increase in joint opening.

It should be noted that the interaction problems occur in small scale while the geotechnical problems are large scale (for instance, subsidence problems); therefore, for arbitration in the results, the unit of joint opening terms is based on the radian. As it can be concluded from the results, regarding different conditions such as stratum materials properties, the magnitude of squeezing loading acting on the segment-stratum interface, etc., the investigation should be performed specifically. This means that defining a regular relation between the joint opening and the joint opening length interaction is not conceivable. 

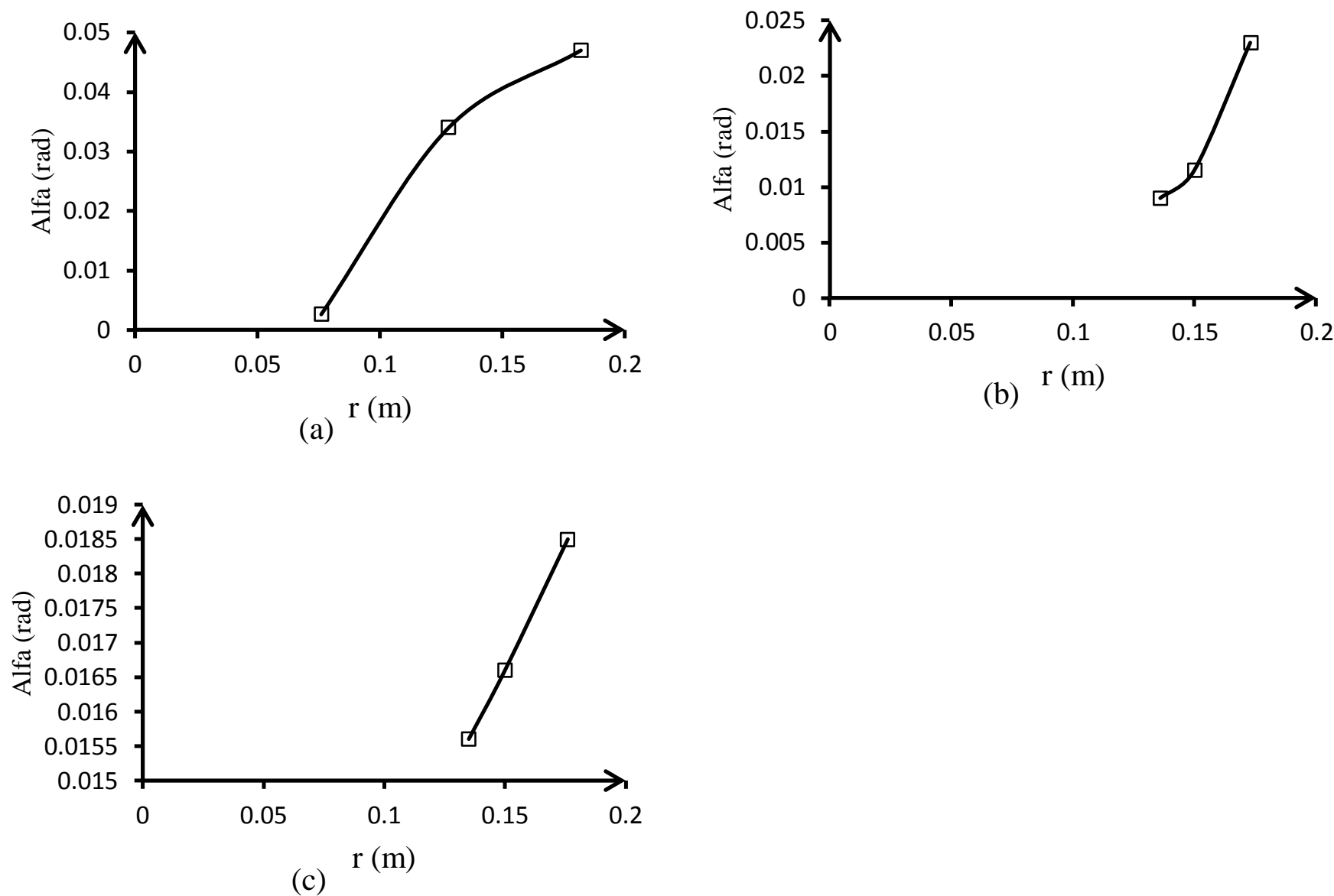

Figure 14. Joint opening versus joint opening length for difference materials: a) Marl b) Shale c) Sandstone

Additionally, the Contacts between the segments which are defined by springs in normal and tangential directions are affected by the local squeezing loading at the segment-rock mass interface. The number of contact elements in longitudinal joint prior to and after loading at the key-segment-stratum interface is depicted in Figure 15. According to this figure, contact elements are influenced by the squeezing loading.

Finally, under the complex situation of loading, the opening of joint occurs and it affects contacts' ability related to the transition of structural loads [14].

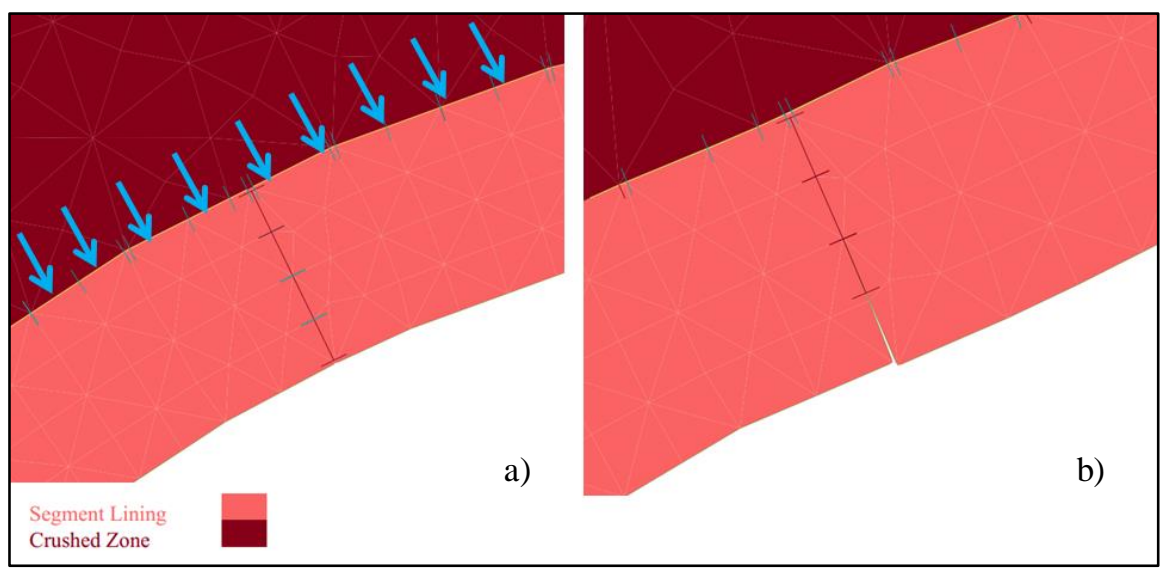

Figure 15. Joint contact: a) Before loading b) After loading

\section{Conclusion}

In conclusion, according to the above mentioned analyses and numerical models investigating the interaction mechanism of concrete lining joints, the following results have been fulfilled. 
Regarding the simulated local load equivalent to the load of the overburden of 30,35 , and 40 meter applied to the interface between weak stratum and segment, along with the gravity load because of weak stratum, following results can be obtained. For one thing, through applying the nonsymmetrical and local load to the interface between segments and weak stratum for three different layers with different strengths, the instability at the location of connecting plan happens for various amount of $\mathrm{k}$; moreover, the amount of longitudinal joint opening at the location of connecting plan results in the incomplete interaction, stress concentration and plastic deformations for different amount of $\mathrm{k}$; for each layer with fixed strengths is variable and there isn't specific paradigm between $\mathrm{k}$ and the amount of longitudinal joint opening. Additionally, the maximum amount of bending moment and axial force at the location of connecting plan occurs for the sandstone layer which has the minimum strength compared to the other layers. The interaction diagram for different loading conditions exposes that instability in segmental tunnel lining under different amount of (k) such as $0.5,1,1.5$ and 2 occurs; as ( $\mathrm{k}$ ) increases, the instability spreads promptly.

As the amount of load increases, radial stress at the location of longitudinal joint increases. This fact leads to increase in the opening of longitudinal joint at the location of segments; besides, the strength of layers influences the opening of the longitude joint. Finally, detailed observation of monitoring information shows that as the strength of layer decreases and the local load at the interface between segments and weak stratum increases, deformations increase. The reduction of thickness in the connecting plan at the location of longitudinal joint leads to an ineffective interaction between segments and therefore each segment has to bear the applied load individually. If this occurs, the interference of axial load and the bending moment from the location of longitudinal joints are incomplete and the opening of joints is resulted. The numerical results also demonstrate that maximum bending moments in longitudinal joints occurred for crushed zone with weaken strengths (Sandstone).

\section{Acknowledgements}

The authors gratefully acknowledge the support of this work by Tehran Regional Water Organization, Mahab Ghodss Consulting Engineering Company, Sabir International Company, Tehran Urban Railway Organization and Tehran Municipality.

\section{References}

[1] Blom, C.B.M., "Design Philosophy of Concrete Linings for Tunnels in Soft Soils, Technical university of Delft". 2002.

[2] Ahmet, G, "Evaluation of Structural Analysis Methods Used for the Design of TBM Segmental Linings", Middle East Technical University, 2010.

[3] Hefny ,A.M., "An Investigation into the Behavior of Jointed Tunnel Lining", Nanyang Technological university, 2006.

[4] Zhu.Zheng, R, "Three Dimensional Numerical Modelling of Shield Tunnelling”, Hohai University, 2008.

[5] Cavarlo, S.H.P, Blom, C.B.M, Walraven, J.C., "Formation and accumulation of contact deficiencies in a tunnel segmented lining." Applied Mathematical Modeling, 36 (2012): 4422-4438.

[6] Do, Ngoc, Dias, Daniel, Oresto, Pier.," 2D numerical investigation of segmental tunnel lining behavior." Tunnelling and Underground Space Technology, 37 (2013) 115-127.

[7] Na Wu, Huia, Shen, Shui, Liao, Shao, "Longitudinal structural modelling of shield tunnels considering shearing dislocation between segmental rings." Tunneling and Underground Space Technology, 50 (2015) 317-323.

[8] Chen, J, "Mechanical Behavior of Segment Rebar of Shield Tunnel in Construction Stage", South China University of Technology, 2008.

[9] Chan, R.P., "Face Stability Analysis of Shallow Shield Tunnels in Dry Sandy Ground Using the Discrete Element Method", Key Laboratory of Soft Soils and Geo-environmental Engineering of Ministry of Education, Department of Civil Engineering, Zhejiang University, 2011.

[10] Salemi, A, Esmaeili, M, Sereshki, F, "Normal and shear resistance of longitudinal contact surfaces of segmental tunnel linings." International Journal of Rock Mechanics \& Mining Sciences, 77 (2015) 328-338.

[11] Vervuurt, A.H.J.M., den Uijl .J.A., "Bezwijkveiligheid Boortunnels, Meetrapport en evaluatie Proevenserie”, 2006.

[12] Teachavorasinskun, S, "Influence of segmental Joints on Tunnel Lining", Department of Civil Engineering, Faculty of Engineering, Chulalongkorn University, 2010.

[13] Güray, A, "Evaluation of Structural Analysis Methods Used for the Design of TBM Segmental Linings", Middle East technical university, 2010.

[14] Hitoshi,T, "Study on Construction Loads During Shield Tunneling Using a Three-Dimensional FEM Model", Metropolitan Expressway Co., 2004. 